\title{
Nairobi centre's director to quit
}

THE World Bank's network of international agricultural research centres has been dealt a serious blow with the departure of Dr A C Allison as director of the International Laboratory for Research on Animal Diseases in Nairobi.

Dr Allison, a distinguished immunologist, was appointed director at Nairobi just cver a year ago. He said on the telephone from Nairobi last week that the decision that he should leave his post was taken at the meeting of the governing council in April. Dr Allison says that he intends to stay in Nairobi until the review of the laboratory's five-year plan is completed in October, and possibly until the next council meeting in the spring of 1981.

Allison is the third director of ILRAD to leave in the six short years of its existence. The first died and the second, like Allison, resigned. It is an open secret that Allison and some members of the scientific and administrative staff at Nairobi have been at loggerheads almost since the beginning. Last week, Allison said that he had not been given the support he had reason to expect from the council itself.

ILRAD is one of the more recently created of the international centres now run by the Consultative Group on International Agricultural Research, a consortium

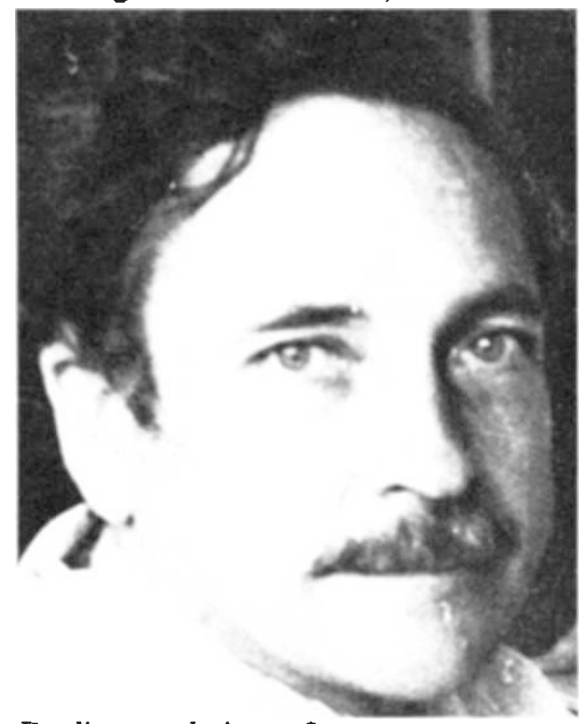

Ex-director designate?

of donor organizations among which the World Bank is the chief contributor. The founder members of the network of nine centres were the wheat and rice research centres in Mexico and the Philippines respectively.

Unlike other centres in the CGIAR network, ILRAD was set up to carry out a somewhat specific task - the protection of animals against trypanosomiasis and theileriosis (or East Coast Fever), a tickborne disease fatal to large proportions of susceptible cattle.

ILRAD's first big success came soon after the foundation of the laboratory in

1974, when a technique for the in vitro culture of trypanosomes was developed. Since then it has seemed that the development of a vaccine against trypanosomiasis, African sleeping sickness, may be complicated by the antigenic variability of the infective organisms as recovered from infected animals.

Still more recently, however, it has appeared that genetic variability is by no means as apparent in the tsetse fly vectors of the disease, which appears to suggest ways in which the disease may be tackled. The prospects of vaccines against theileriosis are, by contrast, bright - some say that another two years may be sufficient.

\section{Short commons for nuclear physics}

\section{Washington}

ONE of the most disruptive effects of the budget battles currently being fought in Washington has been the defeat of several attempts to map out medium-term strategies for the support of basic research. A prominent victim is nuclear physics.

Earlier this year, physicists advising the Department of Energy and the National Science Foundation had proposed - and the Administration had accepted - that stability should be brought to nuclear physics funding by planning for a constant real growth of about three per cent over the next five years (just as three years ago agreement was reached to keep funding level in real terms for high-energy physics).

In particular, about $\$ 20$ million a year would be allocated for the construction or upgrading of research facilities. This would be about one-sixth of the total, and a considerable increase on the average equivalent of $\$ 1.3$ million a year spent over the past two decades.

A list of priorities was agreed with the department and was headed by the superconducting cyclotron now under construction at Michigan State University and a tandem linac accelerator system (Atlas) at the Argonne National Laboratory, for which funds had already been requested in the 1981 budget. Following these were plans for an electrostatic accelerator at Washington University and the upgrading of a tandem accelerator at Yale, with other projects climaxing in a national continuous beam high-energy electron accelerator.

Now the whole scheme is threatening to collapse like a house of cards. In revising its budget request in March, the Administration decided that construction at Atlas should be deferred. And last week the House of Representatives Appropriations Committee, taking a broad swipe at the whole energy research budget, recommended that rather than increase the Department of Energy's budget for nuclear
The laboratory has a permanent staff of some 40 scientists, together with students and visiting fellows. The annual budget is now approaching $\$ 10$ million which has provoked some criticism of the laboratory on the grounds of extravagance. In practice, the costs are not much out of line with those of other laboratories in the World Bank network, and are held to reflect the costs of supporting a largely expatriate staff in developing countries such as Kenya.

The chief anxiety of the laboratory management now appears to be the problem of recruiting their fourth director in six years in circumstances that may appear to potential candidates to be unpropitious.

physics by seven per cent as had originally been proposed, it should be reduced by five per cent below its current 1980 level in 1981 , in real terms a contraction of about 15 per cent. Operating funds would fall to their lowest level since the early 1960 s, and construction costs would be cut from $\$ 13.3$ million to $\$ 9.3$ million by delaying construction of the Michigan machine.

Before the latest cuts, nuclear physicists had been optimistic that they were seeing the end of a decade's decline. Central to this optimism had been the DoE's apparent acceptance of a report prepared by its Nuclear Science Advisory Committee, chaired by Professor Herman Feshbach of the Massachusetts Institute of Technology.

The report sets out a detailed rationale for a slow but steady increase in funding over the next five years. Particular attention is paid to the need for increased funding for new medium-sized and large facilities, as well as the upgrading of existing facilities. But the report also emphasizes that these should not be funded unless "a clear plan of action is developed that shows that the required balance in (national) capability can be retained".

In a normal budget year, this is the type of language that appeals to congressional committees. This year, it has cut little ice, and the promises of the January budget request seem unlikely to materialize.

At the National Science Foundation, for example, the Administration had suggested that the physics budget should be increased by 16 per cent to compensate for the relative growth of the biological sciences during the 1970 s. This figure has been successively cut back, and is unlikely to end up as more than an eight or nine per cent increase.

It is the DoE's budget, however, which is threatened with the most damage. Here the House Appropriations Committee, shifting funds into politically popular dam construction projects, has proposed that the whole of the energy research budget should be kept at roughly the 1980 level, a 
real contraction of about ten per cent.

The cuts would be shared across the board. The high-energy physics budget, for example, would have a proposed growth of 11 per cent cut to three per cent, with a $\$ 20$ million cut in operating funds for the major accelerator laboratories and in particular a $\$ 5$ million cut in funds for the construction of Fermilab's energy saver/doubler.

Administration officials have been working hard behind the scenes, hoping the Senate can be persuaded to mitigate some of the worst effects. Unless the funding prospect improves, there will "really be some sort of chaos and disaster", warns Dr Edward Frieman, director of DoE's Office of Energy Research, predicting in particular that up to 1,500 scientific and technical jobs could be lost at the national laboratories.

So far, nuclear physicists seem to be accepting what is in store for them phlegmatically. Almost two-thirds of the 76 university-based accelerators operating in 1970 have since had to close, many for lack of operating funds.

There is also widespread concern that these developments are putting off potential research students, while the supply of postgraduate research workers is also beginning to dry up. One estimate is that there are currently several hundred vacant teaching and research assistantships.

DoE officials still hope that a reasonable programme can be salvaged. Internal figures being used in planning next year's budget include an increase in nuclear physics funding from $\$ 115$ million to $\$ 130$ million between 1982 and 1986 (in 1980 dollars) - in contrast to level-pegging for high-energy physics.

But nobody pretends that this year's tide can easily be turned. Mr Robert N Giaimo, chairman of the House Budget Committee, told a meeting of the American Association for the Advancement of Science last week that in the near future "there has to be more discrimination between basic research which is likely to be useful and basic research which is not likely to be" and that faced with the prospect of a nonexpanding pie, the competition for funds will get increasingly fierce.

David Dickson

\section{Heidelberg lab \\ Danes drag feet}

A GROUP of Danish scientists who advise the government on the scale and division of Denmark's basic research budget has recommended that Denmark should no longer contribute to the costs of the European Molecular Biology Laboratory, based in Heidelberg. If the Danish government were to accept the advice, it would be a severe blow to the morale - if not the pocket - of the $£ 10$ million a year laboratory, which was launched by an $0028-0836 / 80 / 260606-01 \$ 01.00$ agreement of ten nations in July 1974 and opened in May 1978.

Denmark was obliged to make a decision on EMBL this year. So far, its Natural Science Research Council and its Agricultural and Veterinary Research Councils have been supporting EMBL (to the tune of some $£ 120,000$ a year) out of their own budgets; but it had been agreed in July 1974 that this arrangement should last for only seven years. The source in Denmark of the EMBL contribution for 1981 thus came into question.

Normally in Denmark, subscriptions to international bodies are paid out of government rather than research council funds - that is to say, the sums are allocated from the total research budget before it is divided among the various research councils. So when a committee of scientists from the Natural and Agricultural Research Councils considered who should pay for EMBL in 1981, it attempted to transfer the burden to what it considered to be the rightful place - at government level, but effectively shared among all the other research councils.

None of this need have caused a stir in Heidelberg. In making its administrative recommendation, however, the joint committee chose also to criticise Danish participation in EMBL. For example, the committee pointed out that there is no Dane at the laboratory, and that its programme of research seemed to be rather disjoint from Denmark's.

When this rather qualified recommendation went to the government's science advisory body, the body decided against further participation in EMBL, in the light of tight financial constraints imposed upon it by government.

Denmark thus finds itself in a difficult position. The agreement establishing EMBL was reached as a treaty by West Germany, Austria, Denmark, France, Israel, Italy, the Netherlands, the UK, Sweden and Switzerland, and abrogating it would be a diplomatic matter, as it would be for a nation leaving the high-energy physics laboratory, CERN (on which the EMBL constitution was modelled). However, Danish scientists believe the money will be found somehow, probably by a small group of research councils footing the bill independently, somewhat as before. The new arrangements will have to be complete by mid-October, in time for the Finance Committee of the Danish parliament to consider them in November.

Robert Walgate

\section{Helsinki agreement}

\section{West looks East}

\section{Brussels}

The whole system of West-East technology transfer needs re-examination, according to Charles Levinson, secretarygeneral of the International Federation of Workers in the Chemical Industry. This was one of the few clear ideas to emerge this week from the review by the European Parliament's Political Affairs Committee's of the Helsinki agreements.

Levinson described West-East technology transfer as an inevitably expanding process without any political control of interdependence between Western enterprises and Eastern state trading corporations. The Western entrepreneurs, he said, were providing credits for transfer of capital technology which could then only result in the flooding back of joint production onto Western markets. However, Levinson's grasp of the situation was not echoed by many of his colleagues.

At an international hearing of this kind, it might be supposed that apparent naivety was intended simply to stress a point on the record. However, Dr Guido Carli, former director of the Bank of Italy and now president of UNICE, seemed unaware of several contradictions. Speaking on what the Helsinki agreements call Basket II (economic, scientific, technological and environmental exchange) he accepted unquestioned the CIA estimates that the Soviet Union would become a net importer of energy in 1985 (a forecast which the Soviets emphatically deny).

On the other hand, he failed to rise to a question from the floor on the possible economic threat of increasing West German dependence on gas imports from the Soviet Union. Carli proposed a joint research project into energy saving between the major energy importers, including the Soviet Union, as a future counter to OPEC, yet showed no firm grasp of the statistics and parameters involved.

Professor Stefano Silvestri, of the Institute of International Affairs in Rome, suggested that the EEC's lack of a common "or even serious" energy policy and its consequent dependence on Middle Eastern oil was essentially another aspect of the political and military instability of the Mediterranean area. In general the Mediterranean featured largely in discussions, perhaps because of the presence of Willy Brandt, initiator of the North-South Report on sharing of world resources.

Linkage of the three Helsinki baskets defence, trade and human rights - is a fundamental of Western policy. Max van der Stoel, former minister of foreign affairs of the Netherlands, stressed that dialogue does not have to be "music in the ears of the Eastern states".

The problem of Sakharov, other Soviet dissidents and Charter 77 signatories must, he said, be raised at Madrid. Linkage between Basket II, trade and technology, and Basket I, defence, normally comes to the fore in connection with the transfer of militarily sensitive and strategic technology.

However, Colonel Jonathan Alford of the International Institute for Strategic Studies in London illustrated another 